\title{
A IMPORTÂNCIA DO CONTEXTO PARA A INDEXAÇÃO
}

Resumo: A indexação é um importante processo em um Sistema de Recuperação da Informação (SRI), constituído de duas etapas: análise de assunto e tradução. Sabe-se que a literatura aponta a etapa de análise de assunto como um dos processos mais difíceis de serem realizados, pelo seu caráter subjetivo. Um importante fator que deve ser observado nesse processo é o contexto. O objetivo deste estudo é analisar os diferentes pontos de vista que a importância do contexto tem no processo de indexação, especificamente o contexto sociocognitivo. Esta pesquisa parte de um levantamento bibliográfico, caracterizando-se como exploratória e descritiva. Conclui-se que todas as abordagens apresentadas na literatura pressupõem que o processo de indexação sempre sofre influência sociocultural, e depende do contexto cultural e social específico do indexador e do usuário.

Palavras-chave: Indexação; análise de assunto; contexto; organização da informação e do conhecimento.

\author{
Gercina Ângela de Lima \\ Pesquisadora do CNPq nível 1D. \\ Professora Titular na Escola de Ciência da \\ Informação da Universidade Federal de \\ Minas Gerais (UFMG). \\ limagercina@gmail.com \\ Mariângela Spotti Lopes Fujita \\ Pesquisadora do CNPq nível 1B. \\ Professora do Programa de Pós- \\ Graduação em Ciência da Informação da \\ Universidade Estadual Paulista (UNESP). \\ mariangela.fujita@unesp.br \\ Franciele Marques Redigolo \\ Professora Adjunta da Universidade \\ Federal do Pará (UFPA), Faculdade de \\ Biblioteconomia. Doutora em Ciência da \\ Informação pelo Programa de Pós- \\ Graduação em Ciência da Informação da \\ Universidade Estadual Paulista (UNESP). \\ franciele@ufpa.br
}

\section{THE IMPORTANCE OF CONTEXT FOR INDEXING}

\begin{abstract}
Indexing is an important process in an Information Retrieval System (SRI) consisting of two stages: subject analysis and translation. It is known that the literature points to the subject analysis stage as one of the most difficult processes to be carried out, due to its subjective nature. An important factor to note in this process is context. The aim of this study, more specifically, is to analyze the different points of view that the importance of context has in the indexing process, specifically the socio-cognitive context. This research is part of a bibliographical survey characterized as exploratory and descriptive. It is concluded that all approaches presented in the literature assume that the indexing process always suffers sociocultural influence, and depend on the specific cultural and social context of the indexer and the user.
\end{abstract}

Keywords: Indexing; Subject analysis; Context; Organization of information and knowledge.

\section{INTRODUÇÃO}

A organização da informação está diretamente relacionada à capacidade de aprender, supõe a assimilação de novas informações, sua estocagem e sua acomodação dentro de um determinado contexto. A indexação é um dos processos mais relevantes da Organização da 
Informação em um Sistema de Recuperação da Informação (SRI). Esse processo tem como objetivo gerar uma representação do assunto de um documento, levando em consideração o contexto no qual a informação foi produzida e será utilizada. Assim sabe-se que a representação conceitual de uma área do conhecimento pode ser influenciada pelo contexto (social, cultural, estético, político) no qual ela está inserida. Por contexto entende-se ser uma situação em que um evento ocorre, o qual inclui todos os aspectos da experiência de uma pessoa e do comportamento humano, sendo conectadas essas experiências às experiências de outras pessoas.

A transferência de conhecimento é um processo complexo que depende, em grande medida, de como esse conhecimento é transferido, registrado e disseminado, pois, para ele representar efetivamente a cultura e a experiência de uma comunidade, é necessário que seja compartilhado, levando-se em consideração o contexto no qual foi gerado. À medida que aprendemos, assimilamos novas estruturas e ligações, adicionando informações às estruturas existentes, ou alterando essas estruturas por meio do processo de reestruturação. Nesse caso, a estruturação do conhecimento passa de um processo cognitivo individual a um processo cultural e social de construção da realidade, como uma informação perceptiva que leva em consideração as informações do mundo a que pertencemos e como respondemos a elas, para gerar um conhecimento novo.

Cada estrutura de conhecimento existe como objeto, ideia ou evento e, também, como um grupo de atributos, o qual é ligado a outra estrutura do conhecimento. Assim o contexto auxilia na determinação do significado dos conceitos dessas estruturas. Quando se estabelecem os conceitos em um domínio do conhecimento, de certa forma, eles são determinados a partir da perspectiva do contexto que foi considerado. Barros (2004, p. 109) observa que:

\footnotetext{
Por contexto compreende-se o enunciado que exprime uma ideia completa, no qual o termo estudado se encontra atualizado. A identificação das características de um conceito num contexto é possível graças aos descritores.
}

A definição de um conceito por meio de suas características e predicados, representado pelo seu símbolo verbal, ou seja, o termo, faz com que ele seja contextualizado dentro de uma área específica do conhecimento. O símbolo isolado de seu contexto não poderá ser interpretado e distinguido de outros conceitos que formam o sistema conceitual daquele domínio, mesmo 
possuindo propriedades semânticas relevantes (se elas não forem evidenciadas por meio de sua definição).

É necessário, portanto, conforme Dahlberg (1978), que cada objeto seja definido para fixar os seus limites enquanto conceito pertencente àquele domínio específico. O processo mental da formação do conceito se dá por meio de uma linha de pensamento que leva à elaboração do conhecimento, passando por um processo de assimilação da informação pelo cérebro, transformando-a. Após essa elaboração mental, baseada no conhecimento prévio do indivíduo, a unidade de informação se transforma em uma unidade conceitual, que é representada por um termo, o qual possui um único significado, geralmente expresso por símbolos e palavras, com o objetivo de comunicação.

Dessa forma, a determinação e a representação dos conceitos dos documentos estão ligadas ao discurso e às atividades em um contexto, e o indexador precisa ter uma compreensão desse discurso e desses processos. Assim, em um Sistema de Recuperação da Informação, quando o indexador analisa um documento, deve ter em mente em qual contexto o documento foi produzido, para quem ele será destinado e como ele será recuperado. Para isso, ele deve entender o potencial de uso do documento no ambiente de recuperação, pois supõe-se que não se pode determinar e representar o assunto de um documento analisado sem alguma compreensão do uso futuro dele. Nesse caso, se o indexador levar em conta o contexto no momento da indexação, impactará positivamente na recuperação da informação. Por isso o processo de indexação é importante tanto na representação do conteúdo de um documento quanto na recuperação da informação.

A indexação é realizada com base em duas etapas: a análise de assunto e a tradução. $\mathrm{Na}$ análise de assunto, ocorre a leitura documentária do texto com o objetivo de compreender o conteúdo do documento, identificar os conceitos importantes e selecionar aqueles que são relevantes para a representação do documento, levando em consideração as necessidades dos usuários.

Na etapa da tradução, o indexador utiliza-se de um vocabulário controlado para realizar a padronização terminológica dos conceitos selecionados, com o intuito de evitar a ambiguidade e a polissemia, pois uma expressão linguística pode apresentar mais de um entendimento. Essa multiplicidade semântica pode gerar problemas de interpretações no enunciado, dificultando a 
comunicação, já que uma palavra pode apresentar vários significados e essa representação depende do contexto na qual está inserida.

Destaca-se a necessidade de o indexador possuir conhecimento prévio sobre o assunto a ser indexado, levando em consideração os aspectos linguísticos, lógicos e cognitivos que são exigidos nas estratégias de leitura para a compreensão e interpretação do conteúdo do documento. Nessa perspectiva, os estudos sobre leitura documentária são de suma relevância nesse processo, principalmente para compatibilizar a ideia do autor com a necessidade do usuário, papel este realizado pelo indexador, que é o responsável por fazer essa ponte.

Salienta-se que este artigo é resultado de uma pesquisa mais ampla, que tem como proposta estudar a importância do papel do contexto, tanto na perspectiva do indexador como na do usuário, ou seja, tanto na representação do conteúdo de um documento quanto na recuperação da informação. Portanto apresentam-se os resultados parciais de reflexões realizadas sobre o objetivo deste estudo, que é analisar os diferentes pontos de vista que a importância do contexto tem no processo de indexação, especificamente o contexto sociocognitivo.

Nas próximas seções, apresenta-se, primeiramente, a metodologia, seguida da fundamentação teórica sobre o contexto como variável de indexação, trazendo especificamente os aspectos evolutivos e as abordagens epistemológicas das teorias da indexação, culminando com a apresentação dos diferentes contextos em indexação e, finalmente, as considerações finais.

\section{METODOLOGIA}

Esta pesquisa se caracteriza como exploratória e descritiva, pois parte de um levantamento bibliográfico, com o intuito de fundamentar e descrever os primeiros resultados da pesquisa sobre a importância do papel do contexto da representação e da recuperação da informação.

Para a realização da pesquisa bibliográfica, foram feitos os seguintes questionamentos para direcionar este estudo: (1) sob quais perspectivas o contexto é tratado na literatura?; (2) qual a importância do contexto para a indexação?; (3) qual o papel do indexador nesse processo? 
Para isso, fez-se uma busca exploratória nas bases de dados eletrônicas no Portal de Periódicos da Coordenação de Aperfeiçoamento de Pessoal de Nível Superior - CAPES, a saber: (1) Library Information Science Abstratcs - LISA; (2) SocINDEX; (3) Base de Dados em Ciência da Informação - BRAPCI; (4) Scopus e Web Of Science, utilizando-se as seguintes expressões de busca: ("Contexto e indexação" OR "Context and indexing" OR " Contexto e indexación” OR "Contexto e análise de assunto" OR "Context and subject analysis" OR “ Contexto y análises de contenido).

Constatou-se que os 89 documentos recuperados advinham de várias áreas do conhecimento, principalmente da linguística, ciência da informação e ciência da computação. Realizou-se a análise desses documentos a partir de três critérios: (1) documentos que tratavam do contexto na perspectiva do processo da indexação; (2) documentos que tratavam do contexto na perspectiva da análise de assunto; (3) documentos que tratavam do contexto na perspectiva da recuperação da informação.

Como resultado, obtivemos 12 documentos considerados muito pertinentes, ou seja, $15 \%$ do total recuperado, 28 documentos considerados pertinentes, representando $35 \%$, e 20 documentos pouco pertinentes, $25 \%$, e 20 não pertinentes, também representando $25 \%$. Assim pode-se dizer neste mapeamento que $50 \%$ dos documentos recuperados foram considerados muito pertinentes e pertinentes, conforme ilustrado no Gráfico 1.

Gráfico 1: Pertinência da bibliografia

\section{PERTINÊNCIA DA BIBLIOGRAFIA}

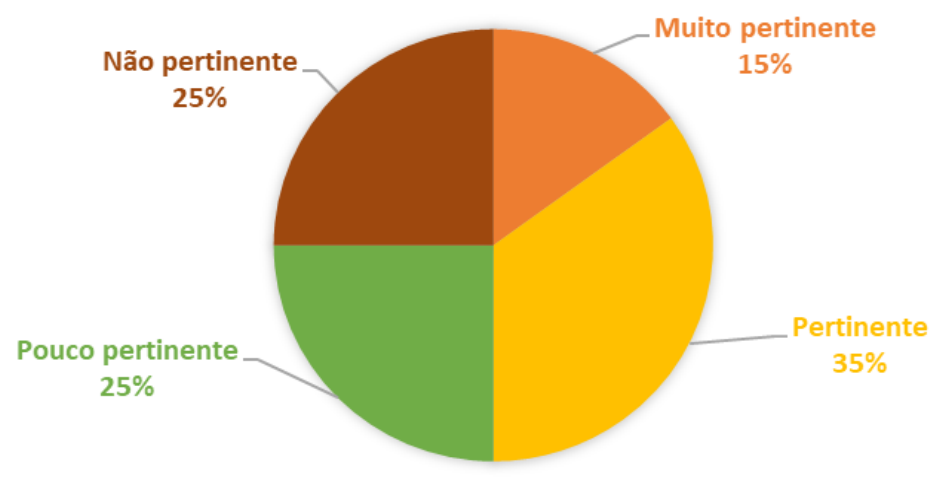

Fonte: dados da pesquisa. 
Aqui não se pretende apresentar um estudo quali e quantitativo desse resultado, pois não é objetivo deste artigo. Porém, conforme descrito anteriormente, este artigo é resultado de uma pesquisa que tem um escopo mais amplo; então decidimos responder ao objetivo proposto a partir de uma fundamentação teórica.

\section{O CONTEXTO COMO VARIÁVEL DE INDEXAÇÃO}

A indexação é um campo teórico único, com características únicas advindas da corrente teórica anglo-saxônica indexing (FUJITA, 2013) cujos aspectos evolutivos são profícuos, tendo em vista sua natureza interdisciplinar com outras áreas do conhecimento que ajudam no seu desenvolvimento e aplicação, conforme visto no Quadro 1.

Quadro 1: Aspectos evolutivos das teorias de indexação

\begin{tabular}{|c|c|}
\hline Décadas & Marcos teóricos \\
\hline 70 & $\begin{array}{l}\text { Na década de 70, abordando aspectos linguísticos e cognitivos, tais como Austin } \\
\text { (1974), Jones (1976), Borko (1977), Cooper (1978) e Fugmann (1979), que forneceram } \\
\text { lastros teóricos para investigações posteriores. }\end{array}$ \\
\hline 80 & $\begin{array}{l}\text { Ainda na década de 80, Fugmann (1985) desenvolveu uma teoria de indexação a partir } \\
\text { de } 5 \text { axiomas relacionados com a estratégia de busca e recuperação em bases de dados } \\
\text { e inicia uma longa discussão sobre política de indexação que antecipa resultados da } \\
\text { busca e recuperação da informação para "ganhar tempo" de busca do usuário; Soergel } \\
\text { (1985) utiliza concepção da indexação orientada pelo documento que não considera o } \\
\text { contexto e as necessidades de usuários. No Brasil, o grupo Temma (SMIT, 1989) é } \\
\text { responsável, da década de } 80 \text { em diante, por trabalhos em Indexação, na linha de } \\
\text { Análise Documentária que aliam aportes teóricos da Linguística, Lógica e da } \\
\text { Psicologia Cognitiva. }\end{array}$ \\
\hline 90 & $\begin{array}{l}\text { Na década de 90, Fidel (1994) aborda a indexação a partir de concepções orientadas a } \\
\text { usuários e suas demandas na recuperação da informação, diferente das concepções } \\
\text { mais exclusivamente orientadas ao documento. Na perspectiva da concepção orientada } \\
\text { pelo usuário, os estudos de avaliação da indexação usam as características ou } \\
\text { qualidades de exaustividade, especificidade, correção e consistência que podem ser } \\
\text { medidas pela recuperação e, ao mesmo tempo, modificar e aprimorar a recuperação. } \\
\text { Albrechtsen (1993) propõe a existência de três concepções de análise de assunto no } \\
\text { processo de indexação: a simplista, a orientada para o conteúdo e a orientada para a } \\
\text { demanda. } \\
\text { Farrow (1991), com um modelo do processo cognitivo da indexação de documentos, } \\
\text { além de Bertrand e Cellier (1995), enfatiza a perspectiva cognitiva da Indexação. Ainda } \\
\text { na década de 90, Lancaster (1993) e Fugmann (1993) aliam teoria e prática e Frohmann } \\
\text { (1990) propõe regras para indexação sem a perspectiva do que ele denomina } \\
\text { "mentalismo". }\end{array}$ \\
\hline 2000 & $\begin{array}{l}\text { A partir de } 2000 \text {, surgem com Mai (2001) a perspectiva da semiótica para análise da } \\
\text { natureza do processo de indexação de assunto e a perspectiva de domínio na indexação } \\
\text { orientada pelo domínio (MAI, 2004). }\end{array}$ \\
\hline
\end{tabular}




\begin{tabular}{|l|l|}
\hline No Brasil, as pesquisas de perspectiva cognitiva na Indexação são desenvolvidas por \\
Fujita (2003), Naves (2000) e Neves (2004). Fujita e Rubi (2006) avançam na proposta \\
de um Modelo de Leitura documentária para indexação de artigos científicos com base \\
em resultados de coleta de dados introspectiva do Protocolo Verbal para observação do \\
processamento mental da tarefa de indexação por indexadores proficientes e \\
aprendizes.
\end{tabular}

Fonte: Almeida, Fujita e Reis (2013).

A natureza interdisciplinar da indexação é demonstrada por sua evolução teórica, mas a base teórica da indexação é reforçada por uma proposta de classificação sistemática das teorias de indexação a partir de teorias epistemológicas: ateorismo, racionalismo, cognitivismo, empirismo, historicismo e pragmatismo (HJØRLAND, 2018), cujas linhas de pensamento são explicadas por teóricos e respectivos conceitos principais, conforme apresentado no Quadro 2.

Quadro 2: Classificação de abordagens epistemológicas de teorias de indexação por Hjørland (2018)

\begin{tabular}{|c|c|c|}
\hline $\begin{array}{l}\text { Visões } \\
\text { teóricas e } \\
\text { linhas de } \\
\text { pensamento }\end{array}$ & $\begin{array}{l}\text { Teóricos citados } \\
\text { por Hjørland } \\
(2018)\end{array}$ & $\begin{array}{l}\text { Conceito principal definidor da linha de } \\
\text { pensamento }\end{array}$ \\
\hline Ateorismo & $\begin{array}{l}\text { Weinberg (2017), } \\
\text { Lancaster (2003). }\end{array}$ & $\begin{array}{l}\text { "Indexação é uma arte, não uma ciência" } \\
\text { (WEINBERG, } 1985 \text { apud HJØRLAND, 2018). }\end{array}$ \\
\hline Racionalismo & $\begin{array}{l}\text { Ranganathan } \\
\text { (1938), Fugmann } \\
\text { (1985). }\end{array}$ & $\begin{array}{l}\text { "O método básico de análise de assunto é } \\
\text { 'analítico-sintético', para isolar um conjunto de } \\
\text { categorias básicas (análise) e então construir o } \\
\text { assunto de qualquer documento, combinando } \\
\text { essas categorias de acordo com algumas regras } \\
\text { (síntese) [...] As regras e princípios são } \\
\text { entendidos como universais e neutros e refletem } \\
\text { uma ordem subjacente" (HJØRLAND, 2018). }\end{array}$ \\
\hline $\begin{array}{l}\text { Cognitivismo } \\
\text { (fundamenta } \\
\text { do no } \\
\text { racionalismo) }\end{array}$ & $\begin{array}{lr}\text { Farradane } & \text { (1977), } \\
\text { Farrow } & (1991), \\
\text { Beghtol } & (1986), \\
\text { David, } & \text { Giroux, } \\
\text { Bertrand- } & \\
\text { Gastaldy } & \mathrm{e} \\
\text { Lanteigne } & (1995) .\end{array}$ & $\begin{array}{l}\text { "Implica uma visão da indexação (assim como } \\
\text { busca de informações e outros processos } \\
\text { relacionados à ciência da informação) de que as } \\
\text { operações intelectuais mais fundamentais são, } \\
\text { em princípio, explicáveis por regras } \\
\text { reconhecidas e tacitamente conhecidas que } \\
\text { geram uma frase de indexação a partir de um } \\
\text { dado texto. A mente humana é entendida em } \\
\text { analogia com um computador, com certos } \\
\text { atributos universais" (HJØRLAND, 2018). }\end{array}$ \\
\hline Empirismo & $\begin{array}{l}\text { Wilson } \quad(1968) \text {, } \\
\text { ISO } 5963(1985)\end{array}$ & $\begin{array}{l}\text { "[...] procedimentos estatísticos numéricos e } \\
\text { técnicas de recuperação baseadas em medidas } \\
\text { estatísticas de similaridade. [...] A regra dos } \\
20 \% \text {, por exemplo, exige que o indexador } \\
\text { escolha assuntos que estejam contidos em pelo }\end{array}$ \\
\hline
\end{tabular}




\begin{tabular}{|c|c|c|}
\hline & & $\begin{array}{l}\text { menos } 20 \% \text { do documento indexado [...]. Os } \\
\text { métodos padrão ISO 5963: } 1985 \text { para examinar } \\
\text { documentos, determinar seus assuntos e } \\
\text { selecionar termos de indexação também parecem } \\
\text { principalmente empiristas, embora nenhum } \\
\text { procedimento empírico real seja apresentado" } \\
\text { (HJØRLAND, 2018). }\end{array}$ \\
\hline Historicismo & $\begin{array}{l}\text { Hjørland (2017), } \\
\text { Austin (1974) }\end{array}$ & $\begin{array}{l}\text { "Abordagens historicistas à indexação são } \\
\text { baseadas no desenvolvimento histórico do objeto } \\
\text { [53] e do sujeito. Enquanto o racionalismo e o } \\
\text { empirismo são epistemologias individualistas, o } \\
\text { historicismo, o pragmatismo e a teoria do } \\
\text { paradigma kuhniano são exemplos de } \\
\text { epistemologias sociais. As epistemologias } \\
\text { sociais negam o pressuposto racionalista de que } \\
\text { o pensamento humano é baseado em processos } \\
\text { cognitivos universais e que a percepção e a } \\
\text { cognição humanas são independentes do } \\
\text { contexto social e cultural em que ocorrem" } \\
\text { (HJØRLAND, 2018). }\end{array}$ \\
\hline Pragmatismo & $\begin{array}{l}\text { Shera (1951), } \\
\text { criador do termo } \\
\text { epistemologia } \\
\text { social; } \\
\text { Olson, (2002) } \\
\text { Austin (1974) }\end{array}$ & $\begin{array}{l}\text { "Teorias pragmáticas e críticas da indexação } \\
\text { estão de acordo com o ponto de vista historicista } \\
\text { de que os sujeitos são relativos a discursos } \\
\text { específicos, mas enfatizam que a análise de } \\
\text { assunto deve apoiar determinados objetivos e } \\
\text { valores e deve considerar as consequências da } \\
\text { indexação. Essas teorias enfatizam que a } \\
\text { indexação não pode ser neutra e que é um } \\
\text { objetivo errado tentar indexar de maneira neutra. } \\
\text { A indexação é um ato. Os atos servem aos } \\
\text { objetivos humanos. Bibliotecas e serviços de } \\
\text { informação [e classificações] também servem } \\
\text { aos objetivos humanos, e é por isso que a sua } \\
\text { indexação deve ser feita de uma forma que os } \\
\text { apoie" (HJØRLAND 2017). }\end{array}$ \\
\hline
\end{tabular}

Fonte: Sistematização realizada pelas autoras com base em Hjørland (2018).

As linhas de pensamento e seus autores expõem características práticas e teóricas de indexação que revelam as bases teóricas da indexação manual e automática. Em específico, Hjørland (2018, p. 25) conclui que "[...] a indexação é sempre influenciada por contextos socioculturais e que esses contextos precisam ser considerados na prática de indexação e teoria, e que os critérios de classificação e indexação devem ser encontrados em critérios pragmáticos”. 
Do ponto de vista da semiótica, Mai (2001) considera que o processo de indexação de assunto realiza um número de interpretações que em algum grau dependem do contexto cultural e social específico do indexador.

Com base na visão teórica do historicismo, é preciso considerar a abordagem sociocognitiva da indexação tendo em vista que a leitura documentária para análise de assunto na indexação é realizada por meio de objetivos e influenciada pelo contexto profissional do indexador que tem na demanda do usuário do sistema de recuperação da informação uma influência direta na compreensão de leitura, além do conteúdo do texto que veicula o assunto principal.

No paradigma social ou construcionista, a abordagem sociocognitiva muda o foco da perspectiva unicamente individual para contextos socioculturais enfatizando o paradigma epistemológico social ou construcionista em uma abordagem metodológica mais ampla e holística, que inclui o estudo da informação, dos sistemas de informação, seus profissionais e usuários.

Hjørland (1997, p. 118) defende a adoção de um "ponto de vista coletivista metodológico" que incorpore a investigação psicológica do indivíduo dentro de uma perspectiva sociocultural e histórica mais ampla, estabelecendo o interno/individual dentro do externo/ambiente e consequentemente integrando os vários níveis de investigação para alcançar verdadeiros sistemas eficazes de representação e recuperação.

Com base na proposta de coletivismo metodológico para o entendimento da Análise de Domínio, Hjørland e Albrechtsen (1995, p. 409) afirmam que:

\footnotetext{
A abordagem de Análise do Domínio reconhece que domínios do discurso incluem atores, que têm visões de mundo, estruturas de conhecimento individual, inclinações, critérios de relevância subjetivos, estilos cognitivos particulares, etc. Em outras palavras, há uma interação entre estruturas de domínio e conhecimento individual, uma interação entre os níveis social e individual.
}

A abordagem cognitiva da leitura documentária em indexação teve grande importância para o conhecimento de estratégias de leitura e de leitura profissional, porém, com o modelo interacionista de Giasson (1993) das três variáveis, texto-leitor-contexto, delimita-se uma abordagem sociocognitiva na qual se observa o conhecimento prévio a partir de seu contexto sociocognitivo, que significa considerar o sistema de informação e seus serviços de organização 
e recuperação de informação, bem como o indexador com seu conhecimento prévio profissional e objetivos em situação de interação durante o processamento textual para os objetivos de indexação.

Com a abordagem sociocognitiva, é possível, segundo Hjørland (2002, p. 258), mudar "[...] o foco da Ciência da Informação de indivíduos (ou computadores) para o mundo social, cultural e científico", considerando-se que "[...] as ferramentas, conceitos, significado, estruturas de informação, necessidade de informação e critérios de relevância são moldados em comunidades de discurso".

A abordagem sociocognitiva, portanto, tem como foco o contexto em que o sujeito realiza uma determinada atividade em perspectiva histórica e cultural, bem como sua cognição em relação ao seu contexto de produção. Evidencia não só a tarefa de indexação de assuntos, mas privilegia e entrelaça as diferentes visões dos usuários que fazem parte do contexto sociocognitivo dos indexadores, pois são usuários dos resultados da tarefa que realizam.

Contexto é uma palavra que, por si só, recomenda uma análise de seu conceito. De forma mais genérica, por exemplo, quando vamos analisar um determinado fato, ocorrência, problema ou mesmo uma situação ou processo, sempre começamos por questionar a existência de um contexto que propiciou condições para o desenvolvimento das ações. É uma concepção análoga, por quanto o contexto explica-se melhor no âmbito da Linguística Textual para situar, não só a produção de um texto, mas sua compreensão por leitores. As concepções de contexto são variadas, mas referem-se especialmente ao texto e, num âmbito que ultrapassa a linguística, às condições sob as quais a língua é falada.

Para os propósitos do estudo em questão e tendo em vista a abordagem interacionista assumida para a leitura documentária, o contexto, como anteriormente enunciado por Giasson (1993, p. 40),

[...] constitui a terceira variável do modelo de compreensão, engloba todas as condições nas quais se encontra o leitor (com as suas estruturas e processos) quando entra em contato com um texto. [...] É possível distinguir três tipos de contexto: os contextos psicológico, social e físico. $\mathrm{O}$ contexto psicológico diz respeito às condições contextuais próprias do leitor, quer dizer, ao seu interesse pelo texto a ler, à sua motivação e à sua intenção de leitura. [...] Por contexto social, devem-se entender todas as formas de interação que podem produzir-se no decurso da atividade... [...] O contexto físico compreende todas as condições materiais em que se desenrola a leitura.... 
Entretanto o contexto, tal como enunciado por Koch (2002, p. 24), a partir da visão de outros teóricos, "abrange, portanto, não só o co-texto, como a situação de interação imediata, a situação mediata (entorno sócio-político-cultural) e também o contexto sociocognitivo dos interlocutores que, na verdade, subsume os demais".

O contexto sociocognitivo, conforme Koch (2002, p. 24), está armazenado na memória do que denomina de "actantes sociais", que entendemos como conhecimento prévio ou cognição, quais sejam: conhecimento linguístico, conhecimento enciclopédico, conhecimento da situação comunicativa e de suas regras, conhecimento superestrutural, conhecimento estilístico, conhecimento de outros textos (intertextualidade). O uso desse conhecimento prévio realizar-se-á através de estratégias.

Conforme Pinto Molina (1992, p. 63), “[...] o termo contexto pode ser interpretado em vários sentidos: no mais extenso, como contexto extralinguístico de uma língua natural, ou seja, o quadro sociofísico no qual a língua em questão é utilizada [...]”. Distingue, assim, além do contexto sociofísico, o contexto individual (psíquico), o contexto social e o contexto cultural. Portanto, além dos contextos físico, psicológico e sociocognitivo, já explicados por Giasson e Koch, acrescentaremos o contexto cultural.

Para a compreensão de como o contexto é visível e condicionante na indexação, elaboramos um parâmetro teórico interdisciplinar comparativo. Na primeira coluna do Quadro 3, trouxemos os aportes teóricos interdisciplinares da Linguística textual sobre os tipos de contexto e comparamos com as perspectivas referentes à indexação ou ao indexador com base na literatura publicada.

Quadro 3: Os diferentes contextos em indexação

\begin{tabular}{|l|l|}
\hline Contexto & Indexação/Indexador \\
\hline $\begin{array}{l}\text { Físico: condições materiais em que se } \\
\text { desenrola a leitura (GIASSON, 1993). }\end{array}$ & $\begin{array}{l}\text { Infraestrutura de equipamentos, } \\
\text { materiais, pessoas e logística disponível } \\
\text { para o desenvolvimento e aprimoramento } \\
\text { do trabalho de indexação em um sistema } \\
\text { de organização e recuperação da } \\
\text { informação (FUJTA, 2004). }\end{array}$ \\
\hline $\begin{array}{l}\text { Psicológico: condições contextuais } \\
\text { próprias do leitor, quer dizer, ao seu } \\
\text { interesse pelo texto a ler, à sua motivação }\end{array}$ & $\begin{array}{l}\text { Dentre os aspectos cognitivos envolvidos } \\
\text { no processo de compreensão da leitura, } \\
\text { tais como interesse, tarefa, objetivo, } \\
\text { conhecimento, normas, opiniões ou }\end{array}$ \\
\hline
\end{tabular}




\begin{tabular}{|l|l|}
\hline e à sua intenção de leitura (GIASSON, & $\begin{array}{l}\text { atitudes, Van Dijk (1979), citado por } \\
\text { 1993). }\end{array}$ \\
Beghtol (1986), postula que objetivo no \\
processo de leitura representa o mais forte \\
argumento na compreensão, pois, \\
segundo o autor, o objetivo de leitura \\
sobrepõe-se a qualquer tipo de estrutura \\
textual. Supõe-se que a definição de \\
objetivos para a leitura documentária atue \\
como facilitador da compreensão e \\
determinação do assunto do documento e \\
deva fazer parte do programa de \\
orientação (FUJTA, 2004).
\end{tabular}

Fonte: elaboração das autoras.

Partindo do princípio teórico de que a leitura é um processo comunicativo entre leitor e texto, consideramos o contexto como uma representação mental do leitor. O contexto, aqui, refere-se ao modelo mental do leitor indexador, no qual estamos supondo existir o processo de 
análise de assunto, a linguagem documentária do sistema, a política de indexação do sistema e seu manual de serviço.

O contexto do indexador é uma variável importante porque estabelece a necessidade de se criarem as condições para a análise de assunto. Esse contexto do indexador pode ser entendido por dois elementos importantes para a formação do seu conhecimento prévio profissional e que o distinguirão de outro leitor: o primeiro elemento é sua formação profissional em Cursos de Graduação e de capacitação em serviço e, o outro, é o ambiente do sistema de informação que o contratou, dotado de política de indexação expressa em um manual de indexação, de uma linguagem documentária, e tendo como objetivo maior o atendimento das demandas de sua comunidade usuária.

Por exemplo:

Nos sistemas de informação, a recuperação está condicionada às condições de armazenagem, de tal forma que, segundo Cesarino (1985), a eficiência de um sistema de recuperação de informação depende muito da qualidade da análise conceitual tanto dos documentos quanto das questões. Segundo Houghton e Convey (1977), as funções de armazenamento e recuperação consistem das seguintes operações:

\section{Armazenamento}

- A análise do assunto pelo indexador.

- A tradução dos conceitos analisados para a linguagem de indexação do sistema.

- A organização dos arquivos pelos quais a base de dados é composta.

\section{Recuperação}

- A análise da questão da busca.

- A tradução da questão em linguagem de indexação do sistema.

- A formulação da estratégia de busca.

Conforme Albrechtsen (1993, p. 221), dependendo dos objetivos institucionais, percebe-se qual a concepção de análise de assunto que o sistema de informação segue e, consequentemente, o indexador levará esse aspecto em questão. Consideram-se, assim, diferentes concepções de análise que certamente afetam o desempenho do indexador enquanto leitor. A esse respeito, Albrechtsen (1993, p. 220) classifica os diferentes pontos de vista em três tipos de concepções: simplista, orientada para o conteúdo e orientada para a demanda. 
- A concepção simplista lida com as informações explícitas dos documentos, considerando o assunto como abstração direta dos documentos.

- A concepção orientada para o conteúdo envolve uma interpretação do conteúdo do documento que vai além da estrutura léxica e, às vezes, gramatical do texto, ou seja, envolve aspectos mais complexos que o processo da concepção simplista.

- A concepção orientada para a demanda considera os dados do assunto como instrumentos de transferência do conhecimento, apontando um encontro pragmático da informação ou do conhecimento.

Embora, de acordo com Naves (1996), as duas últimas concepções - orientada pelo conteúdo e orientada pela demanda - sejam complementares, julgamo-las mais do que complementares: são intrínsecas porque, no momento em que o indexador está lendo e procurando identificar e selecionar conceitos para a determinação do assunto do documento, está objetivando encontrar o assunto que lhe é familiar devido à sua prática de indexação e também definir o que pode interessar ao usuário do sistema de informação.

Dessa forma, o processo de indexação não teria foco somente na entidade (concepção orientada para o conteúdo), mas também no contexto (concepção orientada para a demanda) e deve prever a demanda de informação dos usuários, tendo em vista o amplo contexto de recuperação da informação em que estão inseridos todos os processos de organização da informação.

\section{CONSIDERAÇÕES FINAIS}

A natureza interdisciplinar da indexação é demonstrada por sua evolução teórica no início da década de 1970, com os estudos preliminares sobre os aspectos cognitivos, linguísticos e lógicos que se desdobraram em outros estudos até os dias atuais, trazendo grande contribuição para os estudos sobre indexação. Aliado a isso, esta base é reforçada por estudos de Hjørland (2018) com a proposta de classificação de abordagens epistemológicas de teorias de indexação, na qual o autor apresenta cinco abordagens: ateorismo, racionalismo, cognitivismo, empirismo, historicismo e pragmatismo. Todas essas abordagens pressupõem que o processo de indexação 
sempre sofre influência sociocultural, visto que as interpretações realizadas neste processo dependem do contexto cultural e social específico do indexador e do usuário.

Neste estudo, foi feita uma análise dos diferentes tipos de contextos, com base na literatura publicada, na qual realizou-se uma comparação dos aportes teóricos interdisciplinares da Linguística textual sobre os tipos de contexto com as perspectivas referentes à indexação ou ao indexador.

Os resultados revelam que a determinação e a representação dos conceitos dos documentos estão ligadas ao discurso e às atividades em um contexto e o indexador precisa ter uma compreensão desse discurso e desses processos. Assim, em um Sistema de Recuperação da Informação, quando o indexador analisa um documento, deve ter em mente em qual contexto o documento foi produzido, para quem ele será destinado e como ele será recuperado. Para isso, ele deve entender o potencial de uso do documento no ambiente de recuperação, pois supõe-se que não se pode determinar e representar o assunto de um documento analisado sem alguma compreensão do uso futuro dele. Nesse caso, se o indexador levar em conta o contexto no momento da indexação, impactará positivamente na recuperação da informação. Por isso o processo de indexação é importante tanto na representação do conteúdo de um documento quanto na recuperação da informação.

Destaca-se a necessidade de o indexador possuir conhecimento prévio sobre o assunto a ser indexado, levando em consideração os aspectos linguísticos, lógicos e cognitivos que são exigidos nas estratégias de leitura para a compreensão e interpretação do conteúdo do documento. Nessa perspectiva, os estudos sobre leitura documentária são de suma relevância nesse processo, principalmente para compatibilizar a ideia do autor com a necessidade do usuário, papel este realizado pelo indexador, que é o responsável por fazer essa ponte.

Além disso, é importante para o indexador aprender as estratégias sociocognitivas para auxiliá-lo na interação em diferentes contextos, tendo orientações sobre a cultura organizacional do sistema, bem como sobre a política de indexação. Isso irá auxiliá-lo a construir parâmetros para a representação da informação e alcançar um nível de recuperação da informação com relevância e pertinência.

$\mathrm{Na}$ atuação profissional, os pesquisadores e profissionais da área de indexação e recuperação precisam atender às demandas de diferentes domínios em sistemas de organização e recuperação de documentos. Ressalte-se que um enfoque mais centrado em diferentes 
domínios poderá tornar nossa área mais realista e mais relevante em diferentes ambientes ou contextos.

Conclui-se que a perspectiva sociocognitiva em indexação é necessária porque o objetivo da condensação e representação documentária é a recuperação da informação para a construção social do conhecimento. Na concepção orientada para a demanda, é necessário que a análise de assuntos obtenha visibilidade para usuários potenciais e, para isso, a Ciência da Informação e a Organização do Conhecimento devem conhecer o contexto sociocultural dos documentos e da informação.

\section{REFERÊNCIAS}

ALBRETCHTSEN, H. Subject analysis and indexing: from automated indexing to domain analysis. The Indexer, London, v. 18, n. 4, p. 219-224, Oct. 1993.

ALMEIDA, C. C. DE, FUJITA, M. S. L., REIS, D. M. dos. Peircean semiotics and subject indexing: contributions of speculative grammar and pure logic. Knowledge Organization, 2013.

AUSTIN, D. PRECIS: a manual of concept analysis and subject indexing. London: Council of the British National Bibliography, 1974.

BARROS, L. A. Curso básico de terminologia. São Paulo: Editora da Universidade de São Paulo, 2004.

BEGHTOL, C. Bibliographic classification theory and text linguistics: aboutness analysis, interxtuality and the cognitive act of classifying documents. Journal of Documentation, London, v. 42, n. 2, p. 84-113, 1986.

BERTRAND, A.; CELLIER, J. M. Psychological approach to indexing: effects of the operator's expertise upon indexing behavior. Journal of Information Science, v. 21, n. 6, p. 459-472, 1995.

BORKO, H. Toward a theory of indexing. Information Processing \& Management, v. 13, p. 335-365, 1977.

CESARINO, M. A. N. Sistemas de recuperação da informação. Revista da Escola de Biblioteconomia da UFMG, Belo Horizonte, v. 14, n. 2, p. 157-168, set. 1985.

COOPER, W. S. Indexing documents by Gedanken experimentation. Journal of the American Society for Information Science, New Jersey, p. 107-119, May, 1978. 
DAL'EVEDOVE, P. R. O tratamento temático da informação em abordagem sociocultural: diretrizes de política de indexação em bibliotecas universitárias. 2014. Tese (Doutorado em Ciência da Informação) - Faculdade de Filosofia e Ciências, Universidade Estadual Paulista, Marília, 2014.

DAL'EVEDOVE, P. R.; FUJITA, M. S. L. Estudo sociocultural da comunidade discursiva do tratamento temático da informação em bibliotecas universitárias. Encontros Bibli, v. 18, n. 36, p. 23-50, jan./abr., 2013.

DAHLBERG, I. Teoria do conceito. Ciência da Informação, Rio de Janeiro, v. 7, n. 2, p. 101-107, 1978. Disponível em: http://revista.ibict.br/ciinf/article/view/115/115. Acesso em: 10 abr. 2016.

DAVID, C. et al. Indexing as problem solving: a cognitive approach to consistency. In: KINNEY, T. (ed.). Forging New Partnerships in Information: Converging Technologies: Proceedings of the 58th Asis Annual Meeting 32. Medford, NJ: Information Today for the American Society for Information Science, 1995. P. 49-55. Apud HJØRLAND, 2018.

FARRADANE, J. E. L. Relational Indexing: Introduction and Indexing (also with the title: String indexing: relational indexing: introduction and indexing). London, Ontario: University of Western Ontario, School of Library and Information Science, 1977. Apud HJØRLAND, 2018.

FARROW, J. D. A cognitive process model of document indexing. Journal of Documentation, London, v. 47, p. 149-166, 1991. Apud HJØRLAND, 2018.

FIDEL, R. User-centered indexing. Journal of the American Society for Information Science, New Jersey, v. 45, n. 8, p. 572-576, 1994.

FROHMANN, B. Rules of indexing: a critique of mentalism in information retrieval theory. Journal of Documentation, London, v. 46, n. 2, p. 81-101, 1990.

FUGMANN, R. The five-axiom theory of indexing and information supply. Journal of the American Society for Information Science, New Jersey, v. 36, n. 2, p. 116-129,1985. Apud HJØRLAND, 2018

FUGMANN, R. Subject analysis and indexing: theoretical foundations and practical advice. Frankfurt: Index Verlag, 1993.

FUGMANN, R. Toward a theory of information supply and indexing. International Classification, v. 6, n. 1, p. 3-15, 1979.

FUJITA, M. S. L. A importância teórica e prática da indexação na fundamentação científica da organização e representação do conhecimento. In: DODEBEI, V.; GUIMARÃES, J. A. C. (org.). Complexidade e organização do conhecimento: desafios de 
nosso século. 1. ed. Marília: Sociedade Brasileira de Organização do Conhecimento - ISKO Brasil; Fundepe Publicações, 2013. v. 1, p. 147-159.

FUJITA, M. S. L. A leitura documentária do indexador: aspectos cognitivos e linguísticos influentes na formação do leitor profissional. 2003. Tese (Livre-Docência em Análise Documentária e Linguagens Documentárias Alfabéticas) - Faculdade de Filosofia e Ciências, Universidade Estadual Paulista, Marília, 2003.

FUJITA, M. S. L. A leitura documentária na perspectiva de suas variáveis: leitor-textocontexto. DataGramaZero - Revista de Ciência da Informação, Rio de Janeiro, v. 5, n. 4, ago. 2004.

FUJITA, M.S.L.; RUBI, M. P. Modelo de lectura profesional para la indización. Scire, Zaragoza, v. 12, p. 47-69, 2006.

GIASSON, J. A compreensão na leitura. Lisboa: Asa, 1993.

HJØRLAND, B. Epistemology and the socio-cognitive perspective in information science. Journal of the American Society for Information Science and Technology, v. 53, n. 4, p. 257-70, 2002.

HJØRLAND, B. Indexing: concepts and theory. In: HJØRLAND, B. (ed.). ISKO

Encyclopedia of knowledge organization. [S. l: s. n.], 2018. Disponível em: https://www.isko.org/cyclo/

HJØRLAND, B. Information seeking and subject representation: an activity-theoretical approach to information science. Westport: Greenwood Press, 1997.

HJØRLAND, B. Subject (of Documents). Knowledge Organization, [s. l.], v. 44, n. 1, p. 5564, 2017.

HJØRLAND, B.; ALBRECHTSEN, H. Toward a new horizon in information science: Domain analysis. Journal of the American Society for Information Science, New Jersey, v. 46, n. 6, p. 400-425, 1995.

HOUGHTON, B.; CONVEY, J. On-line information retrieval systems: an introductory manual to principles and pratice. London: Clive Bingley, 1977.

INTERNATIONAL STANDARD ORGANIZATION. ISO 5963. Documentation. methods for examining documents, determining their subjects, and selecting indexing terms. Genève: International Organization for Standardization, 1985. Apud HJØRLAND, 2018.

JONES, K. P. Towards a theory of indexing. Journal of Documentation, London, v. 32, n. 2, p. 118-123, 1976.

KOCH, I. G. V. Desvendando os segredos do texto. São Paulo: Cortez, 2002. 
LANCASTER, F. W. Indexação e resumos: teoria e prática. Brasília: Briquet de Lemos/Livros, 1993.

LANCASTER, F. W. Indexing and abstracting in theory and practice. 3. ed. London: Facet Publishing, 2003. Apud HJØRLAND, 2018.

MAI, J-E. The role of domains, documents, and decisions in indexing. Advances in Knowledge Organization, [Germany], v. 9, p. 207-213, 2004. Trabalho apresentado na $8^{\text {a }}$ International ISKO Conference, 2004, London.

MAI, J-E. Semiotics and indexing: an analysis of the subject indexing process. Journal of Documentation, London, v. 57, n. 5, p. 591-622, 2001.

NAVES, M. M. L. Análise de assunto: concepções. Revista de Biblioteconomia de Brasília, Brasília, v. 20, n. 2, p. 215-226, jul./dez.1996.

NAVES, M. M. L. Fatores interferentes no processo de análise de assunto: estudo de caso de indexadores. 2000. Tese (Doutorado em Ciência da Informação) - Escola de Ciência da Informação, Universidade Federal de Minas Gerais, Belo Horizonte, 2000.

NEVES, D. A. de B. Aspectos metacognitivos na leitura do indexador. 2004. Tese (Doutorado em ciência da informação) Escola de ciência da informação, Universidade Federal de Minas Gerais, Belo Horizonte, 2004.

OLSON, Hope A. The power to name: locating the limits of subject representation in libraries. Dordrecht, The Netherlands: Kluwer Academic Publishers, 2002. Apud HJØRLAND, 2018

PINTO MOLINA, M. El resumen documental: princípios y métodos. Madrid: Fundación Germán Sánchez Ruipérez: Pirámide, 1992.

RANGANATHAN, S. R. Theory of library catalogue. Madras; London: The Madras Library Association; E. Goldston, 1938. Apud HJØRLAND, 2018.

SHERA, J. H. Classification as the basis of bibliographic organization. In: SHERA, J. H.; EGAN, M. E. (ed.). Bibliographic Organization: Papers presented before the Fifteenth Annual Conference of the Graduate Library School July 24-29, 1950. Chicago: University of Chicago Press, 1951. p. 72-93. Apud HJØRLAND, 2018.

SMIT, J. W. Análise documentária: a análise da síntese. 2. ed. Brasília, DF: IBICT, 1989.

SOERGEL, D. Organizing information: principles of database and retrieval systems.

Orlando: Academic Press, 1985. 
VAN DIJK, T. A. Relevance assignment in discourse comprehension. Discourse Processes, v. 2, p. 113-26, 1979.

WEINBERG, B. H. Indexing: history and theory. In: MCDONALD, J. D.; LEVINE-CLARK, M. Encyclopedia of Library and Information Sciences. 4th ed. Boca Raton, FL: CRC Press, 1978-1991. Apud HJØRLAND, 2018.

WILSON, P. Two kinds of power: an essay on bibliographical control. Berkeley: University of California Press,1968. Apud HJØRLAND, 2018. 